\title{
Autoavaliação x autonotação - aproximações e afastamentos na formação de professores autorregulados
}

\author{
Self-assessment versus self-grading - approaches to the education of \\ self-regulated teachers
}

\author{
Elizabete Aparecida Garcia Ribeiro* \\ Universidade Norte do Paraná \\ Giovana Chimentão Punhagui** \\ Universidade Estadual de Londrina \\ Nadia Aparecida de Souza*** \\ Universidade Estadual de Londrina
}

Resumo O desenvolvimento de habilidades docentes pressupõe ações que proporcionem maior responsabilidade e autonomia à aprendizagem. Uma dessas ações é a promoção de atividades autoavaliativas, permitindo consciência da situação da aprendizagem e planejamento de intervenções. Este estudo concentrou-se em determinar o potencial autorregulatório, nas práticas autoavaliativas, realizadas em um curso de Pedagogia. A pesquisa de abordagem qualitativa, na modalidade estudo de caso, contou com a participação de 56 discentes, do último ano do curso de uma universidade pública paranaense. As informações, dos questionários e entrevistas, foram submetidas à análise de conteúdo, permitindo constatar que a maioria dos participantes tem consciência das finalidades da autoavaliação, mas vivenciam a proposição de atividades autonotativas, ou seja, de atribuição de nota para compor média. As práticas realizadas não proporcionam o desenvolvimento de habilidades autorregulatórias.

PALAVRAS-CHAVE: Autoavaliação, Autorregulação, Formação de professores.

Abstract The development of teacher skills estimates actions which provides more responsibility and autonomy towards learning. One of these actions is to promote self-assessment activities, contributing to better awareness of one's own learning and planning of interventions. This study focused on determining the potential for self-regulation of learning in self-assessment practices carried out in an undergraduate Pedagogy course. The research is qualitative, using the case study technique. Fifty-six students from the final year of the course at a public university in Paraná participated in the study. Information from questionnaires and interviews was submitted for content analysis, revealing that most participants were aware of the purposes of self-assessment, but they were found to be conducting self-grading activities, which consists on grading one's own work in order to calculate a grade point average. The practices performed in the course do not encourage the development of self-regulatory skills.

KEYWORDS: Self-assessment, Self-regulation of learning, Teacher Education. 


\section{Introdução}

Almejar um ensino de qualidade, que favoreça a aprendizagem e o desenvolvimento do educando, leva, inevitavelmente, à reflexão do processo de formação docente e às concepções e práticas de ensino e avaliação, as quais são submetidos os futuros professores nos bancos universitários. Afinal, as ações pedagógicas não ocorrem ao acaso, são alicerçadas por concepções construídas ao longo da vida, influenciadas por estudos teóricos, bem como por experiências passadas.

Cabe à formação inicial despertar, nos professores de amanhã, o desejo de superar os desafios, de aprender, continuamente, revendo sempre suas concepções e suas ações. Deste modo, torna-se imprescindível possibilitar vivências permeadas pelo compromisso com a reflexão acerca do processo de ensino/aprendizagem e com o planejamento de ações para aperfeiçoamentos e superações das dificuldades.

Olhar para os próprios passos, analisá-los e neles intervir pressupõe, no entanto, o desenvolvimento de habilidades específicas, somente, alcançadas mediante ações concretas que objetivem maior responsabilidade e autonomia para com a própria aprendizagem. Uma dessas ações refere-se à proposição de atividades autoavaliativas, que, quando empreendidas adequadamente, são altamente propícias a maior independência cognitiva e metacognitiva do aluno. Autoavaliar-se configura-se perspectiva de aprendizagem e não, simplesmente, um procedimento para a composição de um escore. Permite, pelo contrário, a regulação do próprio desempenho e a possibilidade de que essas ações sejam trabalhadas e ensinadas aos futuros alunos desses profissionais.

Reconhecendo a importância dessa prática no contexto de formação docente, questionamentos emergiram: (1) a autoavaliação configura-se prática no curso de formação de professores? Se a primeira for verdadeira, (2) de que maneira os professores do curso têm se valido deste instrumental - como autoavaliação ou como autonotação (composição de um escore)? Estas indagações motivaram o desenvolvimento deste estudo, balizado pelo objetivo: determinar o potencial de autorregulação presente nas práticas de autoavaliação efetivadas em um curso de Licenciatura em Pedagogia.

\section{Percurso metodológico}

Analisar os procedimentos e concepções da prática da autoavaliação exigiu participar de um contexto por um tempo, demandou ouvir as pessoas que participam desse dia a dia, considerando percepções e opiniões que foram manifestas. Assim, a abordagem qualitativa, revelou-se mais pertinente, pois ela "[...] se volve com empatia aos motivos, às intenções, aos projetos dos atores, a partir dos quais as ações, as estruturas e as relações tornam-se significativas." (MINAYO; SANCHES, 1993, p. 244).

Como estratégia metodológica, optou-se pelo estudo de caso, por permitir conhecer, em profundidade, as particularidades e complexidade de uma situação singular (ANDRÉ, 2005), não para julgá-la, mas para compreendê-la. A escolha decorreu da circunscrição do espaço de investigação: um curso de Licenciatura em Pedagogia, de uma universidade pública paranaense, para nele mergulhar, selecionando uma peça - a autoavaliação - para analisá-la minuciosamente, sem perder de vista a totalidade do contexto. 
O curso contava, em 2007, com 66 (sessenta e seis) professores em seu corpo docente, atendendo aproximadamente 615 (seiscentos e quinze) alunos, distribuídos em três turnos: matutino, vespertino e noturno. Entrementes, um olhar retrospectivo direcionou a atenção para os alunos que integram o último ano do curso: 143 (cento e quarenta e três). Todavia, apenas 70 consentiram participar e, destes, 56 o fizeram de maneira plena.

As informações coletadas, mediante questionário ${ }^{1}$ e entrevista semiestruturada $^{2}$, foram organizadas e submetidas à análise de conteúdos temática (FLICK, 2004), quando se busca sentidos e compreensões além do valor aparente. Da apreciação resultaram as categorias: (a) autoavaliação: possibilidade para reflexão e (b) autoavaliação como autonotação, possibilitando a elaboração de um texto, cuja pretensão foi favorecer a melhor compreensão do estudo realizado e suas possíveis contribuições no tocante à utilização da autoavaliação para o desenvolvimento da autorregulação.

\title{
Autoavaliação na formação de professores: possibilidades para a reflexão da própría aprendizagem
}

Os benefícios da prática autoavaliativa como incitadora da reflexão e regulação da aprendizagem, em cursos de formação de professores, estão documentados em pesquisas nacionais e internacionais (HARRES, 2003; BREW; RILEY; WALTA, 2009; CHEUNG, 2009; KOUTSOUPIDOU, 2010; NOLAN; SIM, 2011). Destacase a relevante contribuição deste procedimento para o desenvolvimento profissional docente, conferindo maior responsabilidade à aprendizagem dos saberes necessários ao exercício do seu ofício (VILLAS BOAS, 2001). Estes saberes são variados, pressupondo uma formação inicial sólida e impulsionadora, afinal,

\begin{abstract}
A formação, inicial e contínua, embora não seja o único vetor de uma profissionalização progressiva do ofício de professor, continua sendo um dos propulsores que permitem elevar o nível de competência dos profissionais. Além de aumentar seus saberes e seu savoir-faire, ela também pode transformar sua identidade, sua relação com o saber, com a aprendizagem, com os programas; sua visão da cooperação e da autoridade, seu senso ético [...]. (PERRENOUD, 2002, p. 12)
\end{abstract}

A autoavaliação é essencial para a preparação profissional de professores, pois contempla o autoexame do próprio desempenho para levar ao autodesenvolvimento (BAILEY, 1981). Este ocorre quando o professor adquire uma série de competências que lhe permitem tomar decisões inteligentes a respeito de sua atuação profissional.

A prática da autoavaliação dispõe de várias características positivas para a aprendizagem docente. Ela, além de fornecer "[...] uma forma objetiva e sistemática para documentar o ensino, extrair significado de seu trabalho e compreender a eficácia de seu ensino [...]" (CHEUNG, 2009, p. 49), corrobora para a ampliação do "[...] olhar crítico do que se faz enquanto se faz." (HADJI, 2001, p. 103), favorecendo o autocontrole e a determinação na consecução de atividades, desenvolvendo "[...] processo mental interno pelo qual o sujeito toma consciência dos diferentes momentos e aspectos da sua atividade cognitiva." (Ibid, p. 103). 
O processo autoavaliativo tem o intuito de promover o reconhecimento dos passos dados e, consequentemente, o planejamento daqueles que ainda estão por vir, permitindo, ao aluno autorregular-se e desenvolver-se cognitivamente (REGNIER, 2002). Acreditando na validade deste instrumento avaliativo, para a construção da aprendizagem do educando no ambiente escolar e, também, na futura vida profissional, Boud (1995) apresenta algumas razões para o seu desenvolvimento: (a) automonitoramento individual e verificação de progresso: os alunos monitoram sua própria aprendizagem para se certificarem de que estão em busca do alcance dos objetivos propostos; (b) promoção de boas práticas de aprendizagem e habilidades relacionadas a aprender a aprender; (c) diagnóstico e remediação; (d) melhor desenvolvimento da prática profissional ou acadêmica: tornar-se um profissional reflexivo, uma pessoa que é capaz de pensar criticamente a respeito de sua própria prática, planejar mudanças e observar a efetividade dessas modificações; (e) revisão das realizações como prelúdio para o reconhecimento de aprendizagem; (f) autoconhecimento e autocompreensão, contribuindo para o desenvolvimento do indivíduo.

Os dados da presente pesquisa revelaram que a autoavaliação é um procedimento utilizado por vários professores do curso investigado. Mais de $90 \%$ dos alunos afirmaram ter vivenciado essa ferramenta avaliativa, mesmo que em apenas algumas disciplinas. Parte deles parece compreender as finalidades da autoavaliação, quando reconhecem que as práticas autoavaliativas permitem uma descrição geral em relação as suas aprendizagens. Nas respostas que registraram nos questionários, $78 \%$ dos alunos afirmaram gostar de realizar autoavaliação e apontaram como razão o fato deste instrumento avaliativo proporcionar a reflexão acerca do processo de aprendizagem. Assim eles explicitaram:

Gosto de realizar as autoavaliações, porque é um momento no qual reflito sobre meus conhecimentos, sobre meu esforço e as minhas dificuldades, fazendo uma análise do processo e destacando os aspectos positivos e negativos. (Aluno 18)

Apesar de, muitas vezes, não chegarmos a conclusões satisfatórias, acredito que são produtivas, pois podem ajudar a detectar dificuldades e falhas no meu aprendizado, já que propiciam reflexão sobre meu desempenho, me possibilitando corrigi-las posteriormente. (Aluno 26)

A autoavaliação me leva a refletir sobre meu desempenho na disciplina e em consequência repensar minhas dificuldades. (Aluno 28).

Reflito sobre minhas atitudes e ações, permitindo me organizar e tentar melhorar. (Aluno 31)

É um momento de reflexão sobre a minha aprendizagem para saber o quanto evolui, possibilitando-me repensar sobre o erro e o que não consegui atingir, posso melhor e perceber essa melhora. (Aluno 41)

Posso fazer uma reflexão de minha atuação como discente, reconhecendo minhas conquistas, limitações e dificuldades e assim diagnosticar as possíveis melhoras. (Aluno 49)

A reflexão, a respeito da própria aprendizagem, se manifesta de modo bastante frequente nas respostas, revelando o reconhecimento, pelos discentes, da capaci- 
dade da autoavaliação de levá-los a voltar o olhar para o próprio desempenho e reconhecer seus pontos fortes e o que ainda necessita ser superado. A autorreflexão - um dos primeiros passos rumo à efetivação da autoavaliação - é essencial, e pressupõe o reconhecimento dos objetivos de aprendizagem.

Assim, a primeira e mais difícil tarefa é fazer os alunos pensarem no seu trabalho como um conjunto de objetivos. (BLACK et al., 2003) Quando há esse entendimento, torna-se possível coordenar e controlar as ações, já, por outro lado, é muito difícil alcançar um objetivo sem o compreender, sem ter clareza do que é preciso fazer para atingi-lo (Ibid ,2003). Neste sentido, trabalhar com a autoavaliação implica fazer com que as intenções e os critérios de avaliação fiquem transparentes, permitindo uma visão clara do esperado em confronto com o realizado, no intuito de perceber as aprendizagens efetivadas e/ou por efetivar.

Outro desafio é tornar alunos passivos em ativos (BLACK et al., 2003), capazes de assumir responsabilidade e gerenciar a própria aprendizagem, mesmo porque, a passividade é cruel. Ela limita, até mesmo impede, o desenvolvimento das habilidades para aprender ao longo da vida. Infelizmente, há uma tendência em negar-lhes a possibilidade de determinar o que foi aprendido e, então, planejar intervenções (BOUD; FALCHIKOV, 2006). Isso parece ser uma prática corrente no curso pesquisado, como destacam alguns dos alunos:

Uma das dificuldades da autoavaliação é a falta de costume de pensar sobre a nossa prática, de aluno e de professor também. Temos que pensar, refletir, mas, não conseguimos nem nos expressar, porque não praticamos a autoavaliação. Não é só na avaliação, mas no dia-a-dia mesmo, a cada aula, perceber o que ficou, colocar no papel, refletindo sobre aquilo. Eu não tinha esse costume. Se tivéssemos essa prática de fazer uma reflexão, não uma reflexão no vazio, mas uma reflexão orientada, direcionada não só do senso comum, mas do conhecimento, penso que seria mais fácil. (Aluno B)

[...] existe uma falta de costume muito grande. Não estamos acostumados a nos autoavaliar. Penso que seria necessário um trabalho a longo prazo para que a coisa realmente fluísse. (Aluno C)

O depoimento dos alunos desvela a consciência de que o ato de olhar para o próprio desempenho exige constante direcionamento e prática. Nolan e Sim (2011, p. 122, tradução nossa) salientam que "[...] a habilidade de usar a reflexão sistemática e deliberadamente como uma ferramenta de aprendizagem na prática profissional requer desenvolvimento consciente ao longo do tempo na formação inicial e continuada." Analisar os próprios pontos fortes e as dificuldades, para planejar ações de superação, exige esforço e exercício diário, principalmente quando a caminhada profissional também exige trabalhar para que outros desenvolvam sua aprendizagem da mesma maneira.

Favorecer a autoavaliação, propiciando a reflexão do aluno sobre seus avanços e dificuldades, acerca de seu processo de aprendizagem, contribui com a autonomia e responsabilidade discente pelo aprender, pois as "[...] atividades autoavaliativas forçam os alunos a reexaminarem suas atitudes para com seus papéis e suas responsabilidades com relação à aprendizagem.” (TAN, 2007, p. 114, tradução nossa). Esta característica é apontada por alguns alunos, como se pode observar: 
A autoavaliação é um recurso muito importante e deveria ser mais utilizado, sobretudo no ensino superior, pois permite ao indivíduo, que está em processo de formação, adquirir maior autonomia e responsabilizar-se por sua aprendizagem. (Aluno 22)

A autoavaliação é um instrumento válido quando se deseja desenvolver a autonomia, a autocrítica e a reflexão no aluno. Através deste instrumento avaliativo, o aluno se sentirá mais valorizado ao poder opinar sobre sua aprendizagem, tirando todo aquele poder do professor. (Aluno 12)

Nota-se a preocupação, entre esses discentes, em dispor de subsídios para expandir a sua autonomia, salientando a importância da autoavaliação para o desenvolvimento de maior responsabilidade em seu aprender. Para Tan (2007), os alunos devem estar aptos a planejar e direcionar a sua própria aprendizagem, para serem capazes de buscar situações de aprendizagem sem o auxílio do professor. Por isso, a habilidade de autodirigir a própria aprendizagem é fundamental ao longo da vida. A autoavaliação é considerada essencial para preparar os alunos para aprender fora da escola.

Por esta razão, o exercício da reflexão corrobora para o reconhecimento do que já se consolidou e do que ainda necessita ser trabalhado, para que então o planejamento de ações tenha uma base fundamentada e seja realizado de forma realista. O primeiro passo foi efetuado, porém, para que a autoavaliação contribua, efetivamente, para a aprendizagem, outros são necessários. É preciso planejar, selecionando estratégias propícias à superação dos obstáculos e ao alcance dos objetivos delineados. É indispensável agir, reavaliando os resultados do que foi executado e promovendo aperfeiçoamentos.

\section{Autoavaliação x autonotação: os discentes praticam a autorregulação?}

A autoavaliação configura-se uma opção viável e pertinente para a promoção da autorregulação da aprendizagem pelos alunos (BOUD, 1995). Os elementos, nela dispostos, colaboram para que a maior responsabilização pelas próprias ações aconteça. Porém, "[...] muitas vezes é difícil conscientizar-se de tais dificuldades, posto que o aluno não percebe ou não reconhece outras formas de pensar ou fazer." (SANMARTÍ, 2009, p. 66). Por isso, o direcionamento pelo professor formador se faz altamente importante. Este possui o papel de intervir de maneira a incentivar e proporcionar o desenvolvimento de funções consideradas necessárias à autorregulação. Afinal, a regulação da própria aprendizagem não é alcançada por:

[...] uma proeza da força de vontade. Ela opera por meio de um conjunto de subfunções que devem ser desenvolvidas e mobilizadas para mudanças auto-dirigidas. Nem a intenção ou o desejo para mudar, sozinhos, tem muito efeito se as pessoas carecem de meios para exercitar influência sobre seu próprio comportamento. (BANDURA, 1986, p. 336, tradução nossa)

Segundo o autor, para que o indivíduo realize práticas autorregulatórias, de modo a alcançar as metas estabelecidas, é preciso que compreenda as suas condições cognitivas e ambientais, a situação na qual se encontra a sua aprendizagem. Observar o 
próprio desenvolvimento fornece informações referentes ao desempenho do indivíduo, propiciando meios para formular um julgamento a respeito do próprio comportamento frente às situações. Nesta etapa, o indivíduo obtém indicadores necessários para balizar eventuais mudanças e redirecionar suas ações, de modo a superar obstáculos e alcançar os objetivos estabelecidos. Porém, para que haja monitoramento e mudança, ou aperfeiçoamento de ações, é preciso haver constante avaliação da situação, ou seja, comparação entre o real (ações atuais) e o desejável (objetivos estabelecidos). Esta comparação permite a tomada de decisão a respeito de como adequar o comportamento para chegar ao que se quer alcançar (POLYDORO; AZZI, 2008).

Grande parte dos alunos, participantes desta pesquisa, mostrou entendimento do papel importante do reconhecimento da situação de aprendizagem para desencadear ações autorregulatórias. Todavia, reconheceram, também, que, muitas vezes, ela é apenas uma oportunidade para a autoatribuição de notas. $79 \%$ dos alunos afirmaram que as autoavaliações realizadas em seu curso de formação enfatizavam a autoatribuição de nota e não o trabalho com ações para a melhora da própria aprendizagem. Além disso, $46 \%$ deles adjudicaram às atividades autoavaliativas o propósito de mera melhoria de nota.

É preciso salientar que a preocupação com a nota, principalmente quando esta é determinante para a aprovação ou reprovação, pode "desvirtuar" o sentido da autoavaliação. Isso pode ser observado ao analisar o depoimento de dois alunos, que mesmo reconhecendo a necessidade de autorregular alguns pontos da aprendizagem, não se atribuíram notas baixas, por medo das consequências que poderiam sofrer.

Eu fiz minha autoavaliação escrita, coloquei as dificuldades, todas que encontrei, porque de meus estudos, mas na hora de me atribuir uma nota, tive que atribuir uma nota alta, porque eu precisava da nota... Se eu não me atribuísse aquela nota alta ficaria de exame. (Aluno B)

[...] como é preciso uma média para ser aprovado, penso ser muito difícil um aluno se autoavaliar abaixo desta média. Mesmo achando que falta alguma coisa, que não conseguiu alcançar o objetivo, mesmo não conseguindo escrever nada sobre o entendido depois de uma aula, eu não colocaria uma nota abaixo da média, por medo, pois, sei que isso vai me prejudicar. Um dos problemas é a necessidade de uma média, eu jamais faria isso com a minha pessoa. (Aluno C)

Estes relatos demonstram que, muitas vezes, a autoavaliação, devido a autonotação, se transforma em um jogo de faz de conta, levando o aluno à manipulação da nota, pois somente ela terá validade para fins de aprovação, deixando a autorregulação somente no discurso. Desta forma, preferem salvaguardar suas reputações, pois "[...] reconhecer ou revelar, incompreensões, bloqueios [...] leva a enfrentar uma realidade pouco gratificante, a se colocar em posição de fraqueza, a se privar das vantagens concedidas aos bons alunos [...]" (PERRENOUD, 1999, p. 133), preferem disfarçar a realidade, atribuindo-se uma nota suficientemente boa para livrar-se da punição de uma possível reprovação.

Fica visível que o enfatismo na autoatribuição de nota acarreta o desvio do foco do aluno, da análise de suas ações e do interesse na regulação, para a preocupação em ser aprovado ao final do período letivo (BLACK; WILIAM, 1998; SANMAR- 
TÍ, 2009). Como consequência, não há verdadeiro aprimoramento do conhecimento, ocasionando uma coleção de números que não refletem devidamente as necessidades individuais do aluno.

A autonotação acaba tornando-se, para alguns alunos, uma possibilidade de melhorar a média e garantir a aprovação: reprovar-me, "[...] eu não faria isso à minha pessoa” (Aluno C). Vale ressaltar que esta atitude, embora pareça benéfica, em nada contribui com a aprendizagem e o desenvolvimento do educando. Ele estará enganando a si mesmo, uma vez que, desprezando as falhas no processo educativo, perde a oportunidade de retomá-las e superá-las. Vários alunos demonstraram o desprezo à real função da autoavaliação, quando afirmam que ela somente "contribui para melhorar a média, dependendo do professor." (Aluno 6). Ou que gosta "[...] de realizar autoavaliação, pois é uma possibilidade de atribuir uma nota e melhorar a média." (Aluno 11).

Para outros, a autoatribuição de nota torna-se um conflito interior, pois, mesmo reconhecendo haver carência na aprendizagem, consideram difícil assumir uma nota abaixo da média, afinal é a nota que determinará a passagem, ou não, para etapa sucedânea.

Não gosto de realizar autoavaliações, pois é difícil atribuir-me uma nota máxima ou abaixo da média. (Aluno 8)

Em decorrência da nota, as opiniões emitidas nem sempre correspondem à realidade. (Aluno 14)

Acho complicado atribuir-me uma nota, ela nunca é realmente justa. (Aluno 27)

Não gosto de realizar autoavaliação, tenho medo de não ser justa comigo mesma, atribuindo uma nota que não representa o que aprendi de fato. (Aluno 32)

A autoavaliação mexe muito com o caráter e dá a impressão de que o aluno quer apenas alcançar uma média sem merecimento. (Aluno 47)

É difícil atribuir nota a si mesmo, porque se você está bem não quer dar uma nota baixa. E se está mal, não quer reprovar. (Aluno 48)

A necessidade da autonotação, a falta de confiança na relação professor -aluno, o medo de notas baixas, tudo isso, aliado à falta de conhecimento e de domínio na realização da autoavaliação, acaba prejudicando esta prática avaliativa, pois o peso da nota fala mais alto e não permite que o aluno, mesmo consciente de suas dificuldades, seja sincero, e nem mesmo planeje e execute ações para promover remediações e aperfeiçoamentos. Nessas condições, a autoavaliação distancia-se de seu objetivo, que é o de desenvolver a autorregulação das aprendizagens.

Nos relatos dos alunos, nota-se que os professores parecem não dispor de tempo para tornar as atividades autoavaliativas um hábito a ser implantado durante a formação inicial, promovendo, realisticamente, a autorregulação da aprendizagem. O depoimento a seguir revela este fato:

Um professor aplicou uma auto-avaliação pedindo uma reflexão sobre um determinado texto e em seguida uma auto-atribuição de 
nota. Nesta reflexão deveria constar a contribuição do texto para nosso aprendizado, se tinha mudado alguma coisa, no final deveríamos nos avaliar. A pergunta era: $\mathrm{O}$ que ajudou? Se tivesse respondido: ajudou porque vejo a tecnologia com outros olhos era o meu ponto de vista, mesmo que tivesse escrito apenas uma linha. Eu corri, fiz um monte de coisa, peguei o texto, pois podia consultá-lo, preenchi as três folhas e me dei 90 e ele não levou em consideração o que escrevi, só viu a nota, passou de 90 ele baixou para 70. Ele disse que quem tinha se dado 9 ou mais ele baixou, e quem deu de 7 a 8 ele aumentou a nota. A justificativa dada pelo professor foi que ele considerava que para uma pessoa se dar acima de 9 ela devia estar muito acima mesmo. Eu questionei a nota na pauta, mas ficou assim mesmo. O professor simplesmente foi por uma aritmética, acima de 9 , baixa para 7 e, 7 sobe para 9 . Ele não tinha dados para fazer o que fez. (ALUNO C)

A fala do aluno reflete o descontentamento com relação à atitude do professor frente ao seu trabalho. Sua atitude mostra que o seu objetivo não era promover no aluno percepções com relação aos benefícios do conteúdo para a sua aprendizagem, apesar da atividade revelar tal afirmação. Mas, o valor da nota prevaleceu. Sanmartí (2009, p. 50) afirma que o principal objetivo da autoavaliação é que "[...] os alunos construam um bom sistema interno de pilotagem para aprender e o melhorem progressivamente", ou seja, se tornem autorregulados e não fiquem confusos com relação a que valor numérico poderiam se atribuir. Por isso, é proveitoso dedicar tempo para que os estudantes desenvolvam estratégias metacognitivas (SANMARTÍ, 2009), a fim de que possam estar em constante processo de reformulação de seus saberes na sua caminhada profissional.

É profícuo desejar continuar aprendendo (BOUD, 1995), revendo metas continuamente e traçando novos caminhos, regulando a própria aprendizagem. É significativo atuar para progredir na própria forma de ensinar (BAILEY, 1981). Para tanto, questionar, suscitar a reflexão e intervir corroboram para um olhar atento ao que o próprio indivíduo é capaz de oferecer, intentando o repensar das ações pedagógicas e o desenvolvimento de corresponsabilidade e autonomia para com a aprendizagem.

No entanto, a pesquisa revela que os alunos participantes não vivenciaram esta experiência, pois, como demonstram as suas percepções, seus professores universitários proporcionaram atividades que valorizavam a atribuição de uma nota para o desempenho, deixando de lado - talvez de forma inconsciente - o planejamento e a execução de remediações pelos alunos. Ou até, em alguns casos, cogitaram o olhar reflexivo e atento do aluno ao seu próprio desenvolvimento, mas não utilizaram essas informações como subsídios para instigar mudanças, trabalhar estratégias que poderiam ser eficazes, trabalhar a metacognição e/ou, ainda, repensar a própria forma de ensinar. A voz do aluno caiu por terra, e a nota do sistema falou mais alto.

\section{Tecendo algumas considerações}

A pesquisa permitiu revelar que os estudantes de pedagogia vivenciaram atividades autoavaliativas no período de formação inicial. Ou, pelo menos, acreditaram terem participado desta experiência. A maioria deles revelou, também, que tem consciência das finalidades das práticas autoavaliativas. 
As finalidades delatadas pelos alunos foram compatíveis com a proposta de autoavaliação apresentada neste estudo e, teoricamente, fundamentada em estudiosos como Bailey (1981); Boud (1995); Black e Wiliam (1998); Tan (2007) e Sanmartí (2009). Porém, voltando o olhar para as descrições das práticas autoavaliativas vivenciadas em sala de aula, observa-se traços eminentes de uma perspectiva arraigada na autonotação. Sob a égide deste contexto, faz-se relevante destacar que, na realidade, menos da metade dos participantes experienciou atividades que os levassem a identificar capacidades e dificuldades e os instigassem a pensar e planejar ações interventivas. Poucos tiveram a oportunidade de se autoavaliarem e, por conseguinte, de se autorregularem. O estudo aponta para uma prática de autoatribuição de uma nota para o conhecimento, transparecendo a insegurança de alguns em escolher o seu "rótulo", a satisfação de outros por ter a chance de aumentar a sua média e conseguir aprovação, e o descontentamento de outros por terem de escolher um valor para si mesmos, não enxergando contribuição significativa para a sua aprendizagem.

Apesar de os alunos informarem terem vivenciado situações de autoavaliação, na verdade, foi possível constatar a predominância de proposição, pelos professores formadores, de atividades meramente de autonotação, ou seja, destituídas de exigências reflexivas ou autorregulatórias. Isto se deve ao fato de estarem centradas na atribuição de nota para compor média, sem a qual não há aprovação.

Observa-se, no discurso dos alunos, que concebem a importância da autoavaliação para o desenvolvimento da aprendizagem, porém, nota-se também que não houve vivência deste discurso. A teoria chocou-se com a prática, limitando a experiência. Se não houver vivência concreta de atividades autoavaliativas, provavelmente o ensino de ações metacognitivas para o monitoramento da própria aprendizagem, colaborando para a corresponsabilização, estará enfraquecido ou será esquecido. A reflexão, acerca do próprio processo de ensinar, repensando e replanejando ações para melhorar o aprender dos educandos também poderá não ser uma opção. As bases para aprendizagens futuras poderão estar frouxas, resultando em um simples "o que fazer?" em sala de aula.

Refletir é rever, rever é reconhecer e reconhecer é dispor de subsídios para planejar e/ou replanejar. E aquele que planeja e organiza ideias para conduzir ações pensadas e/ou solucionar percalços do ofício. E autoavaliar o próprio agir é abranger e dar vida a todas essas ações de forma consciente, afinal, ensinar é um ato intencional (TUNES; TACCA; JÚNIOR, 2005).

Tendo em vista a necessidade da implementação de atividades autoavaliativas na formação de professores para que, deste modo, também possam integrá-las em sua prática pedagógica, faz-se importante revisar alguns pontos ressaltados no presente estudo, inerentes a sua formatividade: (a) possibilita reconhecimento dos pontos fortes e das dificuldades em relação à aprendizagem; (b) oportuniza refletir acerca do que é preciso fazer para aperfeiçoar e superar; (c) permite enxergar e/ou delinear objetivos concretizáveis; (d) facilita o monitoramento da própria aprendizagem; (e) concede a oportunidade de provocar mudanças no agir, contribuindo para a regulação da própria aprendizagem; (f) corrobora para a corresponsabilização do aprender; (g) torna possível a prática de estratégias metacognitivas e $(\mathrm{h})$ oportuniza a aprendizagem ao longo da vida. 
Professores são formadores de seres humanos. Ensinar a aprender a aprender não é tarefa fácil. Muito menos conferir voz e vez aos educandos. Não se pode deixar a formação universitária relegada à "solidão pedagógica" (ISAIA, 2003), é preciso que, tanto o professor formador, quanto o futuro professor compreendam os porquês de suas próprias ações e nelas intervenham de forma significativa. É preciso que reflitam, que avaliem e regulem a própria aprendizagem. Quem sabe, este seja o começo para uma aprendizagem duradoura, evitando baixos índices escolares, frustrações e evasões, elementos que assombram a realidade brasileira.

\section{Referências}

ANDRÉ, M.E. D. A. Estudo de caso em pesquisa e avaliação educacional. Série Educacional. v. 13. Brasília: Líber Livro, 2005.

BAILEY, G. D. Teacher Self-assessment: a means for improving classroom instruction. Washington: National Education Association, 1981.

BANDURA, A. Social foundations of thought and action: a social cognitive theory. Englewood Cliffs: Prentice-Hall, 1986.

BLACK, P.; WILLIAM, D. Inside the black box: Raising Standards through Classroom Assessment. Phi Delta Kappan, v. 80, n. 2, oct. 1998. Disponível em: <www.pdkintl.org/kappan/ kbla9810.htm >. Acesso em: 22 fev. 2010.

BLACK, P. et al. Assessment for learning: putting it into practice. Buckingham: Open University Press, 2003.

BOUD, D. Enhancing Learning through self assessment. Oxon: RoutledgeFalmer, 1995.

; FALCHIKOV, N. Aligning assessment with long-term learning. Assessment \& Evaluation in Higher Education, v. 31, n. 4, p. 399-413, aug. 2006.

BREW, C.; RILEY, P.; WALTA, C. Education students and their teachers: comparing views on participative assessment practices. Assessment and Evaluation in Higher Education, v. 34, n. 6, p. 641-657, dec. 2009.

CHEUNG, R. H. P. The Use of Self-Assessment to Foster Students'Learning in Teacher Education: An Experience in Teaching Practice. Action In Teacher Education, v. 31, n. 1, p. 49-57, sept. 2009.

FLICK, U. Uma introdução à pesquisa qualitativa. 2. ed. Porto Alegre: Bookman, 2004.

HADJI, C. Avaliação desmistificada. Porto Alegre: Artmed, 2001.

HARRES, J. B. S. Desvinculação entre avaliação e atribuição de nota: análise de um caso no ensino de física para futuros professores. Ensaio Pesquisa em Educação em Ciências, Minas Gerais, v. 5, n. 1, p. 1-10, mar. 2003.

ISAIA, S. M. A. Professores de licenciatura: concepções de docência. MOROSINI, M. C. (et al.). Enciclopédia de pedagogia universitária. Porto Alegre: FAPERGS/RIES, 2003.

KOUTSOUPIDOU, T. Self-assessment in generalist preservice kindergarten teachers'education insights on training, ability, environments and policies. Arts Education Policy Review, 111, p. 105-111, 2010.

MINAYO, M. C. de S.; SANCHES, O. Quantitativo-qualitativo: oposição ou complementaridade? Cadernos de Saúde Pública, Rio de Janeiro, v. 9, n. 3, p. 237-248, jul./set. 1993. Disponível em: 〈http://www.scielosp.org/pdf/csp/v9n3/02.pdf〉. Acesso em: 19 mar. 2009. 
Elizabete Aparecida Garcia Ribeiro - Giovana Chimentão Punhagui Nadia Aparecida de Souza

NOLAN, A.; SIM, J. Exploring and evaluating levels of reflection in pre-service early childhood teachers. Australasian Journal of Early Childhood, v. 36, n. 3, p. 122-130, set. 2011.

PERRENOUD, P. Avaliação: da excelência à regulação das aprendizagens entre duas lógicas. Porto Alegre: ARTMED, 1999.

. A prática reflexiva no ofício de professor: profissionalização e razão pedagógicas. Porto Alegre: Artmed Editora, 2002.

POLYDORO, S. A. J.; AZZI, R. G. Auto-regulação: aspectos introdutórios. In: BANDURA, A.; AZZI, R. G.; POLYDORO, S. A. J. Teoria social cognitiva: conceitos básicos. Porto Alegre: Artmed, 2008, p. 149-164.

REGNIER, J. C. A auto-avaliação na prática pedagógica. Revista Diálogo Educacional, v. 3, n. 6, maio/ago. 2002

SANMARTÍ, N. Avaliar para aprender. Tradução Carlos Henrique Lucas Lima. Porto Alegre: Artmed, 2009.

TAN, K. Conceptions of self-assessment: what is needed for long-term learning?. In: BOUD, David; FALCHIKOV, Nancy. Rethinking assessment in higher education: learning for the longer term. Oxon: Routledge, 2007.

TUNES, E.; TACCA, M. C. V. R.; JÚNIOR, R. S. B. O professor e o ato de ensinar. Cadernos de pesquisa, v. 35, n. 126, p. 689-698, set./dez. 2005.

VILLAS BOAS, B. M. F. Avaliação formativa e formação de professores: ainda um desafio. Linhas críticas, Brasília, v. 12, n. 22, p. 1-21, jan./jun. 2001.

Notas

${ }^{1} \mathrm{~A}$ transcrição de respostas consignadas nos questionários é identificada pelo número atribuído ao instrumento.

${ }^{2} \mathrm{~A}$ transcrição de respostas concedidas nas entrevistas é identificada por letras.

* Professora Municipal das séries iniciais do Ensino Fundamental de Londrina. Mestre em Educação pela Universidade Estadual de Londrina. Londrina, Paraná - Brasil.

*** Mestre em Educação pela Universidade Estadual de Londrina, Londrina, Paraná - Brasil.

*** Professora Pós-Doutroa da Universidade Estadual de Londrina, Londrina, Paraná - Brasil.

\section{Correspondência}

Elizabete Aparecida Garcia Ribeiro - Universidade Estadual de Londrina, Centro de Educação, Comunicação e Artes. Rodovia Celso Garcia Cid, (PR445) Km 380, CEP: 86057-970 - Campus Universitário, Londrina, Paraná - Brasil.

E-mail: elizabetegr@sercomtel.com.br-punhagui@hotmail.com-nadia@uel.br

Recebido em 01 de dezembro de 2012

Aprovado em 18 de novembro de 2013 